\title{
O papel das crenças de autoeficácia na formação de professores de Física do Ensino Médio
}

Marcelo Alves Barros

mbarros@ifsc.usp.br

Universidade de São Paulo, São Carlos, Brasil

\section{Carlos Eduardo Laburú}

carloseduardolaburu@gmail.com Universidade Estadual de Londrina, Londrina, Brasil

\section{RESUMO}

Este trabalho tem como objetivo investigar alguns fatores que influenciam o desenvolvimento profissional de professores de Física, em particular, aqueles relacionados aos aspectos das suas crenças pessoais sobre ensino e aprendizagem. Utiliza-se como referencial teórico um constructo baseado na Teoria Social Cognitiva (BANDURA, 2005), denominado de crenças de autoeficácia. O desenvolvimento das pesquisas sobre autoeficácia tem chamado a atenção para a necessidade de realização de investigações com o objetivo de compreender como os professores percebem a influência destas crenças, em suas realizações acadêmicas, escolhas, esforço, persistência, perseverança e resiliência. Esta pesquisa é de natureza qualitativa, tipo estudo de caso, e os dados foram coletados a partir de uma entrevista semiestruturada realizada tanto com um professor de Física de uma escola pública do município de São Carlos/SP como um acadêmico do Curso de Licenciatura em Ciências Exatas do Instituto de Física da USP de São Carlos. Os resultados encontrados permitem compreender, em que medida as percepções e crenças pessoais de sucessos e fracassos destes sujeitos determinam o grau de esforço que investem nas atividades de ensino. Com as reflexões aqui produzidas argumenta-se que o constructo das crenças de autoeficácia se concilia, de forma consistente, com os estudos contemporâneos, que consideram a relevância da subjetividade dentro da sala de aula.

PALAVRAS-CHAVE: Crenças. Ensino. Teoria Social Cognitiva. Desenvolvimento Profissional. 


\section{INTRODUÇÃO}

É bastante comum nas escolas encontrar professores que, mesmo quando dotados das competências e habilidades exigidas para o exercício de sua profissão, sentem-se desmotivados para continuarem a investir esforços em direção aos objetivos e metas educacionais, que devem atingir com os alunos. Em geral, tais professores reclamam das dificuldades em manter a disciplina em suas classes e do pouco ou nenhum envolvimento dos alunos com a aprendizagem. Costumam atribuir as causas do fracasso escolar à falta de pré-requisitos de seus alunos, às péssimas condições de trabalho e à perda crescente de autoridade e prestígio.

Também é verdade que se encontra no outro extremo aqueles professores que são apontados pelos colegas, alunos e equipe pedagógica como referência de um bom professor. Estes profissionais são capazes de capturar a atenção e confiança de seus alunos, envolvendo-os ativamente nas atividades propostas em sala de aula, inclusive os chamados alunos-problema. Tais alunos costumam respeitar esses professores como verdadeiras lideranças. Por sua vez, esses professores se esforçam em superar o fracasso escolar de seus alunos, sendo considerados pelos membros da instituição como dedicados, eficazes e inovadores. Gostam de seus alunos, atuando de forma receptiva e atenciosa, o que pode ser evidenciado pelo retorno que recebem dos mesmos.

Como explicar estes diferentes perfis de professores que, muitas vezes, estão inseridos nas mesmas condições de trabalho e lidam com os mesmos alunos? Quais as influências de suas crenças de ensino e aprendizagem sobre as capacidades em exercer controle sobre seu próprio nível de funcionamento e dos eventos, que afetam a sala de aula? Como essas crenças influenciam a maneira como lidam com as experiências de sucessos e fracassos escolares vivenciadas ao longo do seu desenvolvimento profissional?

Mais do que atribuir a estas diferenças de comportamento dos professores uma espécie de "dom" ou "vocação profissional", busca-se apresentar, neste artigo, um constructo teórico baseado na Teoria Social Cognitiva (BANDURA, 2005), denominado de crenças de autoeficácia, que vem sendo utilizado para interpretar os diversos condicionantes, que afetam o desenvolvimento profissional de professores de Física, principalmente, aqueles relacionados aos aspectos das suas crenças pessoais sobre ensino e aprendizagem.

\section{ESTUDOS SOBRE AS CRENÇAS DE AUTOEFICÁCIA DOS PROFESSORES}

No contexto escolar, as crenças de autoeficácia de professores têm recebido a atenção de diversos pesquisadores nas últimas décadas. Tais crenças fazem parte do conjunto de muitas outras crenças (epistemológicas, instrucionais, motivacionais, funcionais etc.) que influenciam como um professor percebe, compreende, pensa e realiza suas ações em sala de aula (KAGAN, 1992; PAJARES, 1996; BZUNECK, 2000).

Em 1991 Brophy (1991 apud BZUNECK, 2001) foi quem demonstrou como surgiu o interesse dos pesquisadores pelas crenças de autoeficácia dos professores, enquanto variável de predição da eficácia do ensino. Segundo este autor, nos anos 1960 e 1970, as pesquisas focalizavam aspectos relativamente 
genéricos do ensino. Para se provar que os professores fazem diferença, havia uma preocupação em se relacionar eventuais progressos dos alunos, que eram medidos por testes padronizados de desempenho, com determinados padrões de manejo de classe. Era muito comum, àquela época, a avaliação do aproveitamento do tempo por parte dos alunos e de como os professores conseguiam assegurar seu engajamento nas tarefas escolares. A partir dos anos 1980, ainda de acordo com Brophy (1980), verificou-se uma sensível mudança de enfoque graças ao emprego de métodos mais refinados de natureza qualitativa, como de entrevistas e estudos de caso, entre outros.

A preocupação dos estudiosos se voltou mais para os processos que ocorrem em sala de aula e a aprendizagem passou a ser medida com referência a esse critério. Além disso, começou haver uma valorização do processo de autorregulação na aprendizagem dos alunos (ZIMMERMAN; BANDURA; MARTINEZ-PONS, 1992).

Foi nesse contexto que os pesquisadores identificaram diferenças entre os professores, em função de seus conhecimentos da matéria e de suas crenças sobre ensino e aprendizagem.

Gibson e Dembo (1984) encontraram que professores com crenças de autoeficácia instrucional elevadas investiam mais tempo na aprendizagem dos alunos, fornecendo ajuda necessária àqueles com dificuldades de aprendizagem e elogiando-os pelas suas realizações. Ao contrário, professores com baixas crenças de autoeficácia instrucional desperdiçavam mais o tempo desistindo facilmente dos alunos, que não obtinham os resultados esperados e os criticando pelas suas falhas. Deste modo, professores que acreditavam fortemente em sua autoeficácia instrucional podiam promover uma aprendizagem mais ativa para seus alunos. Por sua vez, aqueles que duvidavam de sua autoeficácia instrucional construíam ambientes de aprendizagem que eram prejudiciais ao desenvolvimento cognitivo e afetivo dos alunos.

Para Schunk (1991), no contexto escolar essas crenças se tratam de convicções pessoais como, por exemplo, executar uma tarefa em um grau de qualidade definida e diz respeito a uma avaliação pessoal quanto à própria inteligência, habilidade, conhecimento e capacidade. Efetivamente, não significa possuir tais qualidades, mas acreditar que as possua. Para este autor, crenças de autoeficácia elevadas dos professores apareceram relacionadas com melhor desempenho dos alunos, em diversas disciplinas focalizadas; incrementos das crenças de autoeficácia dos próprios alunos, consideradas como variável determinante de sua motivação; e a adoção de estratégias mais adequadas de lidar com os alunos, especialmente, com alunos-problema. Inversamente, professores com percepções mais baixas de autoeficácia se caracterizaram por uma tendência de evitar atividades novas e até de planejá-las. Quando as consideravam acima de suas capacidades, eram menos persistentes no tratamento dos alunos com dificuldades e se mostravam menos dispostos a inserir inovações curriculares.

No mesmo sentido, as interações sociais entre os professores exercem poderoso efeito sobre suas crenças de autoeficácia. O clima geral da escola tem impacto considerável nelas, em que se nota aumento nas crenças de autoeficácia dos professores que percebem, em suas escolas, altos níveis de colaboração entre eles mesmos e os supervisores. Os professores mais jovens e inexperientes, 
com crenças iniciais baixas de autoeficácia, geralmente, têm aumento nessas crenças ao trabalharem cooperativamente com professores mais experientes e com crenças mais elevadas. Assim, as interações com colegas, que propiciem feedback positivo aos procedimentos didáticos empregados pelo professor, contribuem para suas crenças de autoeficácia pessoal, enquanto que um feedback negativo faz diminuir tais crenças.

Não é o caso de se superestimar a importância das crenças de autoeficácia dos professores, porque outras crenças podem ser até mais importantes do que essas para favorecer o ensino. No entanto, um ponto deve ser esclarecido e diz respeito ao fato de que, enquanto outras crenças educacionais são fortemente estáveis e resistentes às mudanças, sendo formadas durante o processo de escolarização dos professores - fruto de uma formação ambiental - por meio da observação das atividades escolares e do comportamento dos diversos sujeitos responsáveis pela tarefa de ensinar, acompanhando o professor durante todo o desenvolvimento de sua trajetória profissional (PAJARES, 1992), as crenças de autoeficácia docente podem variar com o tempo e o contexto, não se constituindo como características estáveis.

Além disso, cabe mencionar que as crenças de autoeficácia dizem respeito a situações bem específicas, pois é em relação a estas que as pessoas se julgam ou não capazes. Entretanto, cabe reiterar aquilo que Bandura (1993) sustenta, de que o clima de uma sala de aula e as metas de realização nela estabelecidas, com as consequências de motivação e de desempenho dos alunos, é determinado em boa parte pelas crenças de autoeficácia dos professores.

\section{FUNDAMENTAÇÃO TEÓRICA}

Atualmente, estudos em Psicologia Contemporânea têm destacado ressurgimento das pesquisas sobre os processos autorregulatórios pelos quais os sujeitos exercem suas ações. Tais processos apresentam aspectos sociais, motivacionais, afetivos e exercem um poderoso papel na forma como as pessoas se colocam frente a determinadas tarefas e a forma como realizam suas escolhas, assim como seu grau de esforço e persistência frente às dificuldades e desafios. Mediante mecanismos de ação pessoal, os sujeitos atribuem causalidade para seu funcionamento psicológico, sendo o mais importante as crenças de autoeficácia, ou seja, as crenças das pessoas sobre as capacidades de exercer um controle sobre os próprios níveis de funcionamento e sobre situações que afetam suas vidas. Deste modo, as crenças de autoeficácia se constituem em uma variável psicológica, que ultrapassa os conhecimentos específicos de uma determinada disciplina e devem focalizar contextos bem determinados, uma vez que é em relação a eles que uma pessoa se julga ou não capaz de realizar uma ação.

As crenças de autoeficácia (Bandura, 1977) surgem do relacionamento de quatro fatores distintos: as experiências positivas, as experiências vicárias, a persuasão verbal e os estados fisiológicos. As experiências positivas se referem às situações em que o sujeito se viu frente a uma situação difícil e conseguiu sucesso no seu enfrentamento, servindo para encorajá-lo a enfrentar outra situação semelhante. Bandura (1977) situa essa dimensão como a mais 
de obter sucesso em situações difíceis. Pelo seu caráter pessoal, este fator é central no conceito de autoeficácia. Examinando os mecanismos autorregulatórios, pelos quais as pessoas exercem controle sobre a motivação, estilos de pensamento e vida emocional, ele situou as experiências de êxito como principal veículo da mudança comportamental. As experiências de êxito, além de possibilitarem mudanças no comportamento, são muito importantes para a estabilidade das mesmas frente a situações ameaçadoras.

As experiências vicárias se relacionam às situações em que a observação da execução de uma tarefa semelhante por outro influencia o desempenho do indivíduo. Quando se vê um dos pares obtendo êxito na execução de uma atividade, fica-se motivado a fazer o mesmo. Esse fator é particularmente interessante no ambiente escolar, no qual as atividades são compartilhadas por uma diversidade de pessoas. A observação da atuação dos pares mais experientes pelos novatos se mostra de grande importância para a motivação dos menos experientes.

A persuasão verbal se refere às situações em que a comunicação entre os pares influencia a motivação dos indivíduos. Esse é um fator importante na situação escolar, na qual o corpo docente de uma instituição determina um determinado discurso, que tanto pode incrementar a motivação como diminuí-la.

Os fatores fisiológicos se referem às reações do organismo do indivíduo quando do enfrentamento de situações ameaçadoras. Sintomas como estresse, suor, dores abdominais e tonturas são comuns nessas situações. A forma como o sujeito conhece e se relaciona com o funcionamento do seu organismo é vital para o nível da autoeficácia.

De acordo com Bandura (1986), o nível de autoeficácia de uma determinada pessoa passa a ser visto como resultante da interação de três fatores principais: os pessoais, os ambientais e os comportamentais. Para o autor, essa interação se caracteriza de uma forma triádica, pela qual os fatores pessoais (as crenças do indivíduo, suas atitudes e seu conhecimento) interagem com o ambiente (os recursos sociais, materiais e o mundo físico) e com o comportamento que reflete as ações dos sujeitos.

O relacionamento entre essas três instâncias (pessoal, ambiental e comportamental) é entendido como um processo dinâmico e interdependente. A constituição do nível de autoeficácia é bastante sensível a qualquer mudança na configuração desses fatores. Nesse sentido, fica explícita a influência dos fatores ambientais e pessoais no comportamento e na autoeficácia dos indivíduos, assim como as implicações dos aspectos comportamentais nas condições ambientais e pessoais.

Segundo Bandura (2005), as crenças de autoeficácia atuam como um elemento fundamental na autorregulação da motivação. As pessoas motivam a si mesmas e orientam suas ações, antecipadamente, pelo exercício da premeditação, formando crenças sobre o que elas podem ou não realizar. Elas antecipam prováveis resultados de sucesso ou fracasso de ações possíveis. Colocam objetivos e metas para si mesmas e planejam modos de ação destinados a ter consciência de um futuro estimado. A premeditação, neste sentido, é traduzida em incentivos e ações apropriadas por meio de mecanismos autorregulatórios. 
Neste trabalho, distinguem-se três diferentes formas de motivadores cognitivos, pelos quais as crenças de autoeficácia operam: atribuições causais, expectativas de resultados e objetivos reconhecidos.

Nas atribuições causais, as crenças de autoeficácia influenciam os mecanismos de causa e efeito. As pessoas que consideram a si mesmas como altamente eficazes atribuem as falhas a um esforço insuficiente; aquelas que consideram a si mesmas ineficazes atribuem as falhas à baixa habilidade. As atribuições causais afetam a motivação, desempenho e reações afetivas, principalmente, por meio das crenças de autoeficácia.

Nas expectativas de resultados, a motivação é governada pela expectativa de que o comportamento produzirá certos resultados e o valor destes resultados. Do ponto de vista das expectativas, a pergunta que se coloca é: "posso realizar tal tarefa?", enquanto que no componente resultado se busca resposta à pergunta: "por que devo realizar esta tarefa?". No entanto, as pessoas agem nas suas crenças sobre o que elas podem fazer, assim como sobre os prováveis resultados do seu desempenho. Deste modo, o potencial de motivação das expectativas de resultados é parcialmente governado por autocrenças de capacidade. Existem incontáveis opções que as pessoas não buscam, porque simplesmente elas julgam que não têm capacidade para a realização.

Finalmente, nos objetivos reconhecidos, a capacidade de exercitar a auto influência por meio de um desafio pessoal e a reação avaliativa para as próprias realizações fornece um maior mecanismo cognitivo de motivação. 0 comportamento é motivado e guiado pelos objetivos reconhecidos atuando no aqui-e-agora, ao invés de projetado em alguma situação futura. Objetivos reconhecidos atuam amplamente através de processos de auto influência, em vez de regular a motivação e a ação diretamente. A motivação baseada em um conjunto de objetivos reconhecidos envolve um processo de comparação cognitiva. Ao gerar uma autossatisfação nas metas adotadas, as pessoas dão um direcionamento para o comportamento e criam incentivos para persistir em esforços até que elas concluam seus objetivos. Elas buscam a autossatisfação, a partir do preenchimento de objetivos avaliados e são impelidas a intensificar os esforços mediante descontentamento com baixos desempenhos.

Em síntese, as crenças de autoeficácia determinam o estabelecimento de objetivos e metas que as pessoas colocam para si próprias, o quanto de esforço elas investem nas tarefas e desafios, o quanto elas persistem diante de dificuldades e falhas na trajetória pessoal e profissional e a maneira como reagem aos eventuais fracassos da experiência. Quando deparadas com obstáculos e fracassos, as pessoas que alimentam dúvidas sobre as capacidades diminuem os esforços ou desistem rapidamente. Aquelas que têm uma forte crença em suas capacidades exercem um maior esforço, quando elas falham para dominar um desafio. A perseverança forte, geralmente, produz efeito nos desempenhos de realizações.

Neste trabalho, enfocam-se conceitos extraídos da Teoria das Atribuições Causais, pois do ponto de vista é a teoria contemporânea que exerce maior influência sobre a motivação acadêmica (WEINER, 1992). Esta teoria incorpora as crenças de autoeficácia no sentido de que enfatiza como as percepções dos sujeitos são influenciadas pela maneira como interpretam os sucessos e fracassos

Página | 129 
de seus esforços pessoais e, deste modo, a tendência futura em realizar determinados comportamentos.

\section{AS CRENÇAS DE AUTO-EFICÁCIA DOS PROFESSORES DE FÍSICA}

Com o intuito de investigar as crenças de autoeficácia de professores de Física em formação inicial e continuada elaborou-se uma entrevista semiestruturada, que foi aplicada para dois grupos distintos: i) quatro acadêmicos do Curso de Licenciatura em Ciências Exatas do Instituto de Física da USP de São Carlos, após a realização do Estágio Supervisionado de Ensino e ii) quatro professores experientes de Física de uma escola pública do município de São Carlos/SP com mais de vinte anos de experiência no magistério.

A metodologia de pesquisa aplicada foi de natureza qualitativa (BOGDAN; BIKLEN, 1994) e as entrevistas realizadas enfatizaram aspectos relacionados às situações de sucesso e fracasso escolar, que são vivenciados tanto pelos licenciandos, ao longo de seus Estágios Supervisionados de ensino, como pelos professores, em práticas cotidianas em sala de aula. O intuito consistiu em explicitar quais os significados atribuídos por eles às experiências profissionais de sucesso e fracasso escolar, assim como a forma como lidavam com os diferentes impasses em sala de aula.

Para este trabalho são apresentados os resultados referentes à entrevista de uma professora e uma licencianda, pois se considerou que tais falas são representativas dos discursos dos demais sujeitos entrevistados em cada grupo e que apresentam o maior número de elementos para a análise dos dados. Um aspecto a destacar diz respeito ao fato de que a licencianda analisada, neste trabalho, realizou seu estágio de observação e regência na sala de aula da professora entrevistada e, portanto, se envolveu com os mesmos alunos em situações didáticas.

A partir da análise se pôde identificar três características marcantes na professora em termos das causas, que atribuiu aos sucessos e fracassos em sala de aula.

A primeira característica está relacionada aos fatores internos, ou seja, a crença da professora na sua capacidade de mudar o comportamento dos alunos: "Você percebe que você consegue mudar o comportamento de algum aluno. Sentar do lado dele e dizer: Faz alguma coisa, você tem capacidade! Então, eu já consegui em alguns casos. Eu percebi mudanças grandes". Atribui a motivação do professor à motivação do aluno: "para o professor ficar motivado, ele tem que ver o aluno motivado também", ou ainda, "o que me desmotiva é a falta de motivação do aluno". No entanto, atribui aos fatores externos a falta de motivação dos alunos como, por exemplo, a condição de vida do aluno e a própria família: "É o meio, a forma como ele vive, a condição de vida, o financeiro, o emocional, tudo. (...) Agora, se ele não tem incentivo em casa; só o incentivo do professor não faz com que ele fique motivado. É muito pouco. Porque o professor tenta, mas ele vai para casa, não faz uma tarefa".

A segunda característica está relacionada com a estabilidade das situações de fracasso. A partir das falas da professora se pode inferir que para ela as 
esforços e do tempo despendidos. Em outras palavras, para a professora, o esforço em tentar mudar o comportamento dos alunos mediante a utilização de outras estratégias de ensino pouco ou nada contribuem para um resultado melhor na sala de aula. Mesmo quando adota o trabalho em grupo como maneira de aumentar a motivação dos alunos, os resultados continuam sendo bastante decepcionantes: "Eu trabalho em grupos, para mudar um pouco essa situação, eu comecei a trabalhar com grupos de alunos todos os dias. (...) Aí comecei a trabalhar com eles sentada do lado do grupo: "Vocês vão mostrar para sala que vocês têm valor, que vocês têm capacidade (referindo a um grupo considerado de alunos-problema)". Aí sentei do lado e falei: "Bom, vamos fazer, vamos trabalhar". A aula seguinte, todos chegaram no horário. Que daí eles perceberam que tinham capacidade. Eu fiquei assim, superanimada. Fiquei muito animada. Aí eles começaram a vir para a escola. Sabe, que para eles já era uma grande coisa. Na aula seguinte, foi o único grupo que respondeu certo uma pergunta. Aí simplesmente um parou de vir, outro parou de vir. Simplesmente pararam de vir. Não voltaram mais".

A terceira característica da professora está relacionada ao fato de se sentir impotente diante de determinadas situações, das quais não pode exercer controle: "Então eu sempre me cobrei muito isso daí. Que todos tenham um bom resultado. Claro que isso é impossível, mas eu sempre me cobrei isso. Aí quando você vê que chega uma hora que até você acaba se estressando. Não, eu vou parar com isso, quem quiser estudar estuda, quem não quer não estuda e danese". Também revela sua angústia em ainda não ter encontrado "um jeito certo" de dar aulas: "as mesmas angústias que eu tinha de quando eu comecei a dar aula, eu ainda tenho hoje. Então, uma coisa que me deixa assim muito angustiada é como dar aula de Física. Dar aula de Física pensando na Física, aquilo que você faz no dia a dia ou dar aula de Física colocando a Matemática no meio? Você vê, isso é uma questão que me angustia até hoje. Estou me aposentando, e não consegui resolver direito isso ainda".

Ao procurar relacionar sua formação acadêmica com a capacidade de motivar os alunos em sala de aula, a professora relata a importância da sua experiência prática: "Você vai aprender quando você tiver a sua turma. Você vai aprender ali. No estágio, você vai aprender como passar o conteúdo, como aplicar uma prova. Agora, lidar ali com o aluno, vai ser no dia a dia mesmo. Estágio, eu acho que estágio não é para isso, até porque hoje se você deixar um estagiário em uma sala é complicado. Ele fica assustado. Apesar dele ser aluno ainda e saber como é; ele fica assustado. Agora, quando ele entra e fala: "Não, eu vou trabalhar. Eu vou dar aula para essa turma. Essa turma é minha. A responsabilidade é minha." É completamente diferente. Eu passei por isso. Eu senti isso. Quando eu vim aqui; que eu vim substituir um professor, fazendo faculdade ainda, era diferente de vir fazer o estágio. Quer dizer, agora eu vou ter que dar prova, vou ter que no final do ano dar conta disso; então, eu tenho que resolver o que acontecer aqui. Então, eu acho que é você, é a vivência mesmo que te faz ir criando essa forma e tal de resolver".

A seguir são analisadas as respostas da mesma entrevista fornecida por uma licencianda. Um ponto que se deve chamar a atenção está relacionado com o julgamento da licencianda sobre a capacidade de ter condições para promover a motivação em sala de aula: "Eu acredito que sim, porque eu tento a toda aula. 
Toda aula é até complicado fazer uma aula diferente da outra, né? Mas eu tento sempre levar uma coisa nova, questões do cotidiano que estimulem o aluno".

É interessante destacar o fato de que, ao contrário da professora que mesmo procurando implementar outras estratégias de ensino em sala de aula não obteve resultados positivos, a licencianda relata a experiência de sucesso ao promover o trabalho em grupo, em sala de aula, e o quanto isto foi gratificante para ela: "Eu acho que sair um pouco daquela linha reta e seguir uma estratégia determinada, ter variações, ser inovador, eu acho que contribui muito. (...) É a gente sempre trabalhava em grupo, para começo de história, os alunos eram separados sempre em grupos. Eles responderam em grupo mesmo, e aí a gente deu um espaço de tempo, e depois de duas semanas, a gente corrigiu de novo em grupo com uma conversa com eles. Cada grupo falava: "não, mas eu respondi dessa maneira. Nós respondemos dessa outra". Até que eles chegavam à conclusão de qual era a resposta mais certa, e eles debatiam comigo. Eu fiz dessa maneira, e eu achei que esse exercício foi bem legal. Eles se animaram para resolver".

Primeiramente, pode-se destacar que a licencianda se referiu exclusivamente às experiências de êxito que marcaram o estágio de docência atribuindo as causas do seu sucesso à capacidade de implementar a motivação em sala de aula, ou seja, a fatores internos. Por outro lado, também atribuiu a motivação em sala de aula à relação professor-aluno e não exclusivamente a si mesma: "Eles até queriam que eu continuasse até o final do ano letivo. Alguns alunos pediram. Mas, eu acho que está na relação mesmo de professor com aluno".

Novamente, a licencianda demonstrou uma forte crença pessoal em modificar o comportamento dos alunos, quando foi questionada sobre como se julgava capaz de lidar com aqueles alunos mais apáticos em sala de aula, demonstrando a estabilidade de suas crenças mesmo diante de dificuldades externas: "Então, teve várias vezes que eu chamava aqueles alunos que estavam mais apáticos, conversava com eles da matéria, durante a resolução de exercícios. Sentava no grupo e ajudava eles a resolver. Então, isso acabou estimulando eles. Teve um aluno que, no começo, estava com notas muito baixas, em torno de dois, três pontos, aí com o passar do tempo, quando ele mudou de grupo, e eu comecei a passar mais, eu já ia mais ao grupo deles, que eu percebia que eles precisavam mais de ajuda; ele começou a se esforçar e pediram aulas de revisão de manhã; e ele compareceu em todas, tanto que a última nota dele acho que foi oito; em torno disso".

Outro elemento importante da análise das falas da licencianda diz respeito às causas de sucesso ser devido a fatores controláveis, ou seja, situações nas quais ela acredita que possa alterar assim que desejar: "E eu como vou ser professora, mas já passei por todo o estágio, eu não me sentia bem em saber que o aluno não ia aprender por falta de vontade, então eu acho que era um dever meu mesmo, tentar mudar alguma coisa na sala de aula, na forma de ensinar, na maneira de comunicar, para prender a atenção daquele aluno".

Em nenhum momento, a licencianda se refere a algum elemento negativo, que tenha vivenciado como uma experiência de fracasso ou frustração, sempre se mostrando bastante confiante e motivada intrinsecamente: "Eu não lembro, durante o estágio, de nenhum momento que eu não tivesse vontade de ir até o 
colégio e dar aula. Não teve, até não teve episódios que eu precisasse chamar a atenção do aluno. Eu nunca tive, ainda não tive situações assim, não passei por essas experiências".

No caso da licencianda, pouca ou nenhuma relação é apontada entre a formação acadêmica e a utilização de estratégias motivacionais em sala de aula, sendo muito mais um atributo pessoal do que uma competência profissional adquirida durante os anos de formação para o magistério: "No meu caso, acho que eu consegui motivar os alunos porque eu ainda sou motivada a dar aula de Física, gosto. Por causa disto, mas se eu for relacionar ao que eu aprendi aqui, muito pouca coisa eu consegui utilizar lá na prática, muito pouca coisa". Ou ainda: "Eu não consegui relacionar muita coisa do que eu aprendi. Mas o que a gente aprende aqui na Universidade, eu acho que ainda é muito pouco. Deveria ser dado desde o primeiro ano e mais específico para o Ensino Médio".

Uma consideração importante está relacionada ao fato de que tanto a professora como a licencianda interpretaram as experiências de tal maneira a manter uma autoimagem positiva de si mesmas, ou seja, elas atribuíram o sucesso ou fracasso de algumas situações a fatores que visavam fazê-las se sentirem o melhor possível consigo mesmas, em função da imagem que tinham de si, suas perspectivas e expectativas. Esta característica tendeu a manter a professora entre dois polos: o primeiro, no qual se atribuiu os sucessos das tarefas acadêmicas a seus próprios esforços ou habilidades; o segundo, quando relacionava as causas do fracasso a fatores externos e incontroláveis. Já no caso da licencianda, a característica marcante foi sua referência unicamente aos aspectos positivos de sua experiência de ensino como fatores bastante estáveis e controláveis, sendo as únicas situações desfavoráveis para a realização de provas e a deficiência dos alunos em Matemática como algo, que contribui para a desmotivação de um professor em sala de aula.

No caso da professora analisada se pode atribuir as seguintes características: referiu-se essencialmente a fatores negativos que representavam situações de fracasso escolar, sendo tais fatores externos, estáveis e incontroláveis. Ao contrário, para o caso da licencianda se pode caracterizá-la da seguinte forma: referiu-se, exclusivamente, aos fatores positivos da sua experiência enquanto estagiária, sendo tais fatores internos, estáveis e controláveis.

Estes resultados são particularmente importantes, pois permitem compreender em que medida as percepções e crenças pessoais de sucessos e fracassos tanto de professores em serviço como em formação inicial determinarão o grau de esforço, que investirão nas atividades de ensino. Além disso, as próprias percepções de uma pessoa sobre as situações de sucesso ou fracasso determinam o quanto de esforço esta pessoa empreenderá em situações futuras. Nos casos analisados, a professora se considera como ineficaz e atribui as falhas a pouca habilidade, que possui para lidar com as experiências de fracasso escolar, enquanto que a licencianda se julga como altamente eficaz e atribui as falhas à falta de esforço necessário para obter êxito em uma determinada tarefa.

\section{CONSIDERAÇÕES FINAIS}


Investigações baseadas nas crenças de autoeficácia avaliam os julgamentos que professores em formação inicial e continuada fazem de si mesmos a respeito de suas capacidades para realizar uma tarefa acadêmica. Para o que interessa neste artigo, é importante dizer que a crença de autoeficácia não é um traço global da personalidade, mas é relativa a uma situação específica. No contexto escolar, isto diz respeito às convicções pessoais sobre a capacidade de se resolver uma determinada tarefa. Não se trata de possuir tais capacidades, mas de acreditar que as possua. A intensidade das crenças de autoeficácia depende da interação entre fatores intrínsecos e extrínsecos. Os fatores intrínsecos (pessoais) se referem às particularidades de cada indivíduo, no caso, o professor ou licenciando frente a uma determinada atividade. Os fatores extrínsecos (ambientais e sociais) se referem àqueles que não pertencem à esfera individual. Nesta perspectiva, o funcionamento psicológico de um professor passa a ser visto como resultante da interação desses fatores, ou seja, as crenças dos indivíduos, suas atitudes e seus conhecimentos interagem com os recursos sociais e materiais disponíveis, o mundo físico e social, o que reflete as ações. Isto se mostra interessante na medida em que explica a situação de muitos professores e licenciandos, que se sentem motivados em algumas situações escolares e desmotivados em outras.

O estabelecimento de um alto nível de crenças de autoeficácia em um professor determina uma maior consciência de suas capacidades e limitações na execução de uma tarefa específica. Isso é importante, principalmente, no enfrentamento de uma situação particularmente difícil ou inesperada. Logo, o aparecimento de um eventual fracasso em uma determinada situação relacionada a uma coleção de resultados satisfatórios, por parte do professor dificilmente diminuirá a motivação do mesmo. Por outro lado, um resultado positivo diante de um quadro de resultados negativos, provavelmente, não aumentará a motivação. Segundo Bandura (1986), um incremento no nível de autoeficácia dos indivíduos é necessário na medida em que possibilita proporcionar melhorias nas suas características psicológicas.

Dessa forma, pessoas que apresentam um alto nível de crenças de autoeficácia costumam possuir maior liberdade na escolha de execução de tarefas específicas, pois a preferência é dada para situações semelhantes àquelas nas quais foram obtidos sucessos anteriores. As crenças de autoeficácia estão relacionadas também aos níveis de esforço e resistência a adversidades, encorajando os indivíduos no enfrentamento de situações difíceis e adversas. Pessoas que possuem um baixo nível dessas crenças costumam desistir mais facilmente e são menos imunes a resultados inesperados.

A possibilidade de adequações das linguagens e das representações mais pessoais, de maior proximidade cognitiva e subjetiva, permite elevar o nível de autoeficácia dos professores, já que os mesmos se tornam mais efetivos nas execuções de suas ações. Isto potencializa maior motivação e confiança, o que os habilita a buscar uma melhor forma de atuação em suas atividades. De fato, sujeitos motivados mostram melhores padrões emocionais e de pensamento, costumam possuir menor quantidade de pensamentos negativos, maior serenidade e concentração.

Pelos elementos destacados neste trabalho é possível constatar que na sala de aula coexistem um conjunto de elementos subjetivos, que vão de encontro às perspectivas das pesquisas das décadas anteriores, que entendiam a 
aprendizagem como um processo que poderia ser moldado por fatores cognitivos e universais. Consequentemente, uma prática de ensino que incorpora a dimensão da subjetividade dos sujeitos se torna condizente com a variabilidade de elementos encontrados na sala de aula, que ultrapassam o domínio da cognição. Basicamente, isto se deve a uma maior adequação às peculiaridades do perfil subjetivo (VILLANI et al., 2001) de cada professor e a seu estilo de docência.

Deste modo, estimular os professores a participarem de múltiplas atividades é estabelecer uma aproximação potencial com as suas estruturas cognitivas, com as suas particulares dimensões psicológicas e estilos subjetivos de docência. Particularmente, é razoável supor que um baixo nível de crença de autoeficácia de professores pode ter origem em fracassos contínuos, quando se lhes imputa, de primeiro, uma forma e um modo exclusivo de ensinar que estejam, substancialmente, afastados de seu estilo subjetivo. Uma maneira de aproximar esses níveis passa, então, pelo estímulo da crença do sujeito na sua capacidade de resolver com êxito as atividades propostas, o que produz motivação por mobilização (CHARLOT, 2000).

Como foi possível constatar neste trabalho, os professores e licenciandos variam em motivações e preferências em relação ao estilo ou ao modo de ensinar, assim como na sua afinidade com o conhecimento. Variam igualmente em habilidades mentais específicas ou crenças das mesmas, nível de motivação e interesse para com a Física, persistência dedicada a um problema, de como abordá-lo, além de experiências vividas ou vínculos mantidos com o grupo social a que pertencem ou com outros professores. Esses fatores certamente influenciam, entre outros, na qualidade e na profundidade do ensino.

Com as reflexões expostas procura-se ultrapassar uma leitura simplista que venha a defender a inclusão de variáveis psicológicas sem uma maior fundamentação teórica, argumentando que o constructo das crenças de autoeficácia expostas se concilia, de forma consistente, com os estudos contemporâneos (LABURÚ; BARROS; SILVA, 2011), que consideram a relevância da subjetividade dentro da sala de aula. 


\title{
The role of self-efficacy beliefs in the training of high school Physics teachers
}

\begin{abstract}
This study aims to investigate some factors that influence the professional development of Physics teachers, in particular those related to aspects of their personal beliefs about teaching and learning. As a theoretical reference, it is used a study based on the Cognitive Social Theory (BANDURA, 2005), called self-efficacy beliefs. The development of selfefficacy research has drawn attention to the need to carry out the research in order to understand how teachers perceive the influence of these beliefs on their academic achievements, choices, effort, persistence, perseverance and resilience. This research has a qualitative nature, as a case study, and the data were collected from a semi-structured interview conducted by the presence of both, a Physics teacher from a public school in the municipality of São Carlos / SP and an undergraduate degree in Science Exams of the Institute of Physics of USP of São Carlos. The results showed the extent to which the personal perceptions and beliefs of successes and failures of these subjects determine the degree of effort they invest in teaching activities. With the reflections produced here, it is argued that the construct of self-efficacy beliefs is consistently reconciled with contemporary studies that consider the relevance of subjectivity within the classroom.
\end{abstract}

KEYWORDS: Beliefs. Teaching. Cognitive Social Theory. Professional development. 


\section{REFERÊNCIAS}

BANDURA, A. Social Foundations of Thought and Action: A Social Cognitive Theory. Englewood Cliffs, N.J.: Prentice Hall. 1986.

BANDURA, A. Perceived Self-Efficacy in Cognitive Development and Functioning. Educational Psychologist, v. 28, n. 2, p.117-148, 1993.

BANDURA, A. Self-Efficacy: Toward a Unifying Theory of Behavioral Change.

Psychological Review, v. 84, n. 2, p.191-215, 1977.

BANDURA, A. The evolution of social cognitive theory. In: SMITH, K. G.; HITT, M. A. (Eds.). Great Minds in Management. [S. I.]: Oxford University Press, 2005. p.9 35.

BOGDAN, R.; BIKLEN, S. Investigação Qualitativa em Educação: Uma Introdução à Teoria e aos Métodos. Lisboa: Porto Editora, 1994. (Coleção Ciências da Educação).

BZUNECK, J. A. As crenças de auto-eficácia dos professores. In: SISTO, F. F.; OLIVEIRA, G, C.; FINI, L, D. T. (Orgs.). Leituras de Psicologia para Formação de Professores. Petrópolis, RJ: Editora Vozes, 2000. p.115-134.

BZUNECK, J. A. Crenças de auto-eficácia e o seu papel na motivação do aluno. In: BORUCHOVITCH, E.; BZUNECK, J. A. (Orgs.). A motivação do aluno: contribuições da psicologia contemporânea. Petrópolis, RJ: Editora Vozes, 2001. p.116-133.

GIBSON, S.; DEMBO, M. H. Teacher Efficacy: A Construct Validation. Journal of Educational Psychology, v. 76, n. 4, p.569-582, 1984.

KAGAN, D. M. Professional Grouth among preservice and beginning teachers. Review of Educational Research, v. 62, n. 2, p.129-169, 1992.

LABURÚ, C. E.; BARROS, M. A.; SILVA, O. H. M. Multimodos e múltiplas representações, aprendizagem significativa e subjetividade: três referenciais conciliáveis da educação científica. Ciência e Educação, v. 17, p. 469-487, 2011.

PAJARES, F. M. Teachers' beliefs and educational research: cleaning up a messy construct. Review of Educational Research, v. 62, n. 3, p. 307-332, 1992.

PAJARES, M. F. Self-Efficacy in Academic Settings. Review of Educational 
SCHUNK, D.H. Self-Efficacy and Academic Motivation. Educational Psychologist, v. 26, n. $3 / 4$, p.207-231, 1991.

VILLANI, A.; ARRUDA, S. M.; LABURU, C. E. Perfil conceitual e/ou perfil subjetivo? In: ENCONTRO NACIONAL DE PESQUISA EM EDUCAÇÃO EM CIÊNCIAS - ENPEC, 3. Atibaia, 2001. Atas... Atibaia, SP: ABRAPEC, 2001. [Cd-rom].

WEINER, B. Human Motivation. Metaphors, theories and research. Newbury Park., Ca.: Sage, 1992.

ZIMMERMAN, B. J.; BANDURA, A.; MARTINEZ-PONS, M. Self-motivation for academic attainment: the role of self-efficacy beliefs and personal goal setting. American Educational Research Journal, v. 29, n. 3, p. 663-76, 1992.

Recebido: 06 mar. 2017

Aprovado: 30 maio. 2017

DOI: http://dx.doi.org/10.3895/etr.v1n1.5891.

Como citar:

BARROS, M. A.; LABURÚ, C. E. O papel das crenças de autoeficácia na formação de professores de Física do Ensino Médio. Ens. Tecnol. R., Londrina, v. 1, n. 1, p. 124-138, jan./jun. 2017. Disponível em:

<https://periodicos.utfpr.edu.br/rbqv/article/view/5891>. Acesso em: XXX

Correspondência:

Marcelo Alves Barros

Av. Trab. São-Carlense, 400, Parque Arnold Schimidt, São Carlos, São Paulo, Brasil.

Direito autoral:

Este artigo está licenciado sob os termos da Licença Creative Commons-Atribuição 4.0 Internacional.

\section{(c) (1)}

